\title{
POROSITY: III. WATER AS AN ABSORPTION LIQUID
}

By Edpward W. Washourn and Frank F. Footitr

\author{
ABSTRACT
}

Classes of absorption methods.-The ordinary immersion method has been shown by previous investigators to be unreliable. Simple immersion in low vacuo without boiling is also shown theoretically to be unreliable. An analysis of the results of previous investigators indicates the presence of unsuspected sources of error.

Effect of adsorbed gases upon dry weights of test pieces.-Dry air is shown to be without appreciable infuence. Depending upon the humidity of the atmosphere, adsorbed water vapor may cause errors up to 2 per cent in the porosity value. Perfectly dry fired clay will remove water from conc. $\mathrm{H}_{2} \mathrm{SO}_{4}$ and from fused $\mathrm{CaCl}_{2}$.

Saturation by boiling at atmospheric pressure.-A one hour's (and in one instance a 5 hours') boiling failed to saturate completely. On continued boiling the saturated weight increases linearly with the time and this in spite of the fact that appreciable quantities of dissolved materials are removed from the test piece by the hot water. This result is shown to be due to a gradual and continuous rehydration of the clay by the hot water. The error from this factor may amount to as much as $3 \%$ and the error from dissolved materials to as much as $2 \%$, during a 3 hours' boiling. The nature of the dissolved material was determined.

Method of cooling the test piece.-It is recommended that the test piece be kept in a closed vessel over $95 \%$ sulphuric acid for several hours before its dry weight is taken.

Saturation procedure.-A vacuum method is described in which water may be employed as the saturation liquid under conditions where the above sources of error are reduced to a minimum. The method is not however recommended as a primary standard.

Necessity of a soaking period.-It is shown from theoretical considerations that a soaking period is necessary and methods are given for calculating and for measuring the minimum soaking period required for a given test piece and a given liquid of known penetrativity.

\section{An Analysis of the Results and Conclusions of Previous Investigators}

11. The Experiments of Beecher.-The only comparative studies of the different methods in use for measuring porosity by the absorption process which we have been able to find de- 
scribed in the literature are those of M. F. Beecher ${ }^{7}$ and of F. W. Walker, $\mathrm{Jr}^{8}{ }^{8}$ In Beecher's investigation comparisons were made of the results obtained by the "immersion" method, ${ }^{9}$ by the "boiling-in-air" method, by the "vacuum method," and by combinations of these methods.

Beecher's results with the immersion method show beyond question that this method can not be depended upon to effect complete saturation of a ceramic body even after long soaking. This confirms the results of other investigators ${ }^{10}$ on this point, and demonstrates the inadequacy of this method for the purpose of securing accurate porosity data. This conclusion is moreover in entire harmony with the theory of the mechanism of saturation by immersion which has already been discussed. ${ }^{11}$

As regards the other two methods, Beecher reached the following conclusions:

"Immersion in a vacuum showed slightly lower results on the average than the boiling treatment. From the data presented, it was decided that for ordinary laboratory work where the time element as well as accuracy is a factor, and where the results are for comparison only, within a given study, saturation by boiling for 45 minutes to one hour is sufficient for porosity and absorption determinations. Treatment with the vacuum alone does not offer better results."

From the data which he gives it is not clear that the vacuum which he employed was sufficient to boil the water. He states that the test pieces were "immersed and subjected to a vacuum of 29 " for three hours." Now under a vacuum of 29 " (i. e., a pressure of $25 \mathrm{~mm}$.) water will boil only if its temperature is maintained at $26^{\circ} \mathrm{C}$, (about $78^{\circ} \mathrm{F}$ ) and Beecher's paper contains no information concerning the temperature of the water in his experiments. If the water did not boil steadily, his experiments

${ }^{7}$ Beecher, Trans. Am. Ceram. Soc., 18, 73(1916).

${ }^{8}$ Walker, Ibid., 18, 446(1916).

"In the "immersion" method, a piece of the porous material is immersed in water for several hours and is then removed and weighed. On the assumption that all of the pores have been filled by water, the porosity is then calculable. In the so-called "boiling-in-air" method, the piece is boiled for a stated time in distilled water under atmospheric pressure. The procedure in the "boiling-in-vacuo" and "immersion-in-vacuo" methods is obvious.

${ }^{10}$ Ries, Trans. Am. Ceram. Soc., 9, 699(1907). Purdy and Moore, Ihid., 9, 693(1907). Walker, F. W., Jr., op. cit.

"See Part I, Sec. 6. 
can scarcely be said to furnish a fair comparison of the two methods because the slow part of the absorption process is the last part, that is, the removal of the last traces of air from the pores of the body and this part of the process can obviously not be materially hastened by immersion under a vacuum insufficient to boil the liquid. A pump which maintains a vacuum of $29^{\prime \prime}$ is quite good enough provided the water is kept warm enough to boil steadily. In the absence of any information concerning this point in the case of Beecher's experiments they can not, of course, be regarded as evidence of the superiority of the "boiling-in-air" method over that of "boiling-in-vacuo."

Furthermore, his conclusions that "where absolute accuracy is the important consideration, a combination of boiling, with the vacuum treatment, and a soaking period is the most effective means of saturation," will require modification in the light of some new information pointing to the existence of a hitherto apparently unsuspected source of error.

An analysis of his data as to the effect of a soaking period after boiling shows that, with the exception of one experiment ${ }^{12}$ (which in the absence of any confirmatory experiments must be rejected because of its wide deviation from the others), the additional soaking period apparently produces on the average an increased absorption of only $0.18 \pm 0.07$ gram of water. Beecher states that his experimental procedure consisted in drying the test pieces with a soft towel and weighing them to a "tenth of a gram." With such a procedure, it might be doubted whether much significance should be attached to differences as small as 0.18 gram but for certain cases, theory indicates the necessity of a reasonable soaking period and this aspect of the subject will be more fully discussed below. (Sec. 29.)

12. Walker's Experiments.-Walker's experiments were in many respects similar to those of Beecher, although made upon biscuit wall tile, while Beecher employed grogged clay. Walker employed a vacuum of $28^{\prime \prime}$ and evidently the water used was not warm enough to boil under this vacuum. It is thus clear that in neither of these investigations was the vacuum method given a really fair test.

12 The 13 th experiment recorded in his table II. 
Walker, however, correctly suggests that the "boiling-in-vacuo" method, if properly carried out, should give the best results. ${ }^{13}$

In cases where it can not be carried out, Walker suggests a five hours' boiling at atmospheric pressure. As evidence that such a long period is necessary in order to insure complete removal of the air from the pores, he presents a graph which shows that the absorption of water increases linearly with the time. In view of the linear nature of this increase, there is evidently no assurance that the absorption is complete even at the end of five hours. As far as can be judged from the data presented, the absorption must continue to increase at the same rate, if the boiling is continued beyond five hours. On the evidence presented, therefore, it seems hardly justifiable to recommend the long boiling period of five hours.

It seemed to the writers that the results of Walker's experiments were rather to be interpreted as pointing to the existence of a hitherto unsuspected source of error in the "boiling-in-air" method, one which might prove so important in certain classes of bodies as to condemn the method entirely as a standard method for the determination of porosity values where a high degree of accuracy is sought. The present investigation had, therefore, as one of its first objects, the clearing up of the apparently anomalous behavior exhibited by the results of Walker's experiments.

\section{Preparation of the Test Pieces}

13. Preparing and Shaping.-The body employed in the following tests was made from a common brick shale which was crushed with the aid of a jaw crusher and rollers, and then, without screening, was mixed with tap water until somewhat stiffer than a stiff mud brick. A 25-1b. batch was worked by hand on a marble slab, wedged into shape for the barrel of the briquette machine, and forced through the $1^{\prime \prime}$ square die. The first trial was free from lamination and was wire-cut into four-inch

1s But he implies that "expensive equipment" is essential. Such is, however, not the case. The method could have been successfully carried out with the equipment at his disposal, if water at a temperature of not less than $100^{\circ} \mathrm{F}$ had been employed. Judging from the boiling temperatures tabulated in Walker's paper, he was aware of this possibility, but for some reason, not obvious, he failed to make use of it. 
pieces, fifty pieces being obtained from the batch. After air drying, the pieces were placed in a steam drier for 12 hours.

14. Firing.-An $8 \times 16 \times 2$ inch slab was placed in the bottom of the kiln, and this was covered with a second slab supported by two bricks, thus forming a chamber in which the briquettes were set in 2 ranks of 3 high and 2 files, making 6 piles with 6 briquettes in a pile, or 36 in all.

The kiln was closed in the usual manner and the burn started with wood, followed by soft coal. The water smoking continued for 2 hours, the temperature being raised $50^{\circ}$ per hour for 4 hours and held for 2 hours at $200^{\circ}$. Oxidation was complete at $700^{\circ}$. The temperature was then raised about $30^{\circ}$ per hour and 12 samples were drawn at $950^{\circ}$. These were placed in hot sand and allowed to cool slowly. Twelve more samples were similarly drawn at about $1050^{\circ}$. At $1150^{\circ}$ the last 12 samples were drawn, the total time of burning being about 31 hours.

15. Selecting and Preparing the Briquettes for Test.-From the briquettes prepared and burned as just described, three of each class were selected, that is, 3 drawn at $950^{\circ}, 3$ at $1050^{\circ}$, and 3 r at $1150^{\circ}$. These were selected so as to be as free as possible from cracks and other imperfections. If any superficial cracks or holes were discovered, they were enlarged with a knife so as to be sure that no pockets were hidden beneath them. No cracked briquettes were employed. The entire surfaces of the $950^{\circ}$ and $1050^{\circ}$ briquettes were made as smooth and as uniform as possible, and all corners and edges rounded by polishing with sandpaper. In the case of the $1150^{\circ}$ briquettes, this smoothing was done with the aid of a file, since the briquettes were too hard to be affected by the sandpaper. The nine briquettes prepared in this way were then placed in the drying closet and heated at $120^{\circ}$ for six hours. It was first desired to ascertain the effect of the nature of the atmosphere upon the "dry weight" of the test pieces. This was carried out as described below.

\section{Effect of Adsorbed Gases upon the "Dry Weight" of the Test Piece}

16. Adsorbed Water Vapor.-Four desiccators were prepared, the first one containing " $1.86 \mathrm{sp}$. gr." $\mathrm{H}_{2} \mathrm{SO}_{4}$, the second 
52 per cent $\mathrm{H}_{2} \mathrm{SO}_{4}$, the third 33 per cent $\mathrm{H}_{2} \mathrm{SO}_{4}$, and the fourth one pure water. The relative humidity of the air in these four desiccators was approximately 0 per cent, 3.3 per cent, 67 per cent and 100 per cent, respectively. The briquettes were removed from the drying chamber at $120^{\circ}$, placed in the first desiccator and allowed to cool over the concentrated sulphuric acid. They were then weighed as rapidly as possible in order to obtain their approximate dry weights, after which they were heated to a second time to $120^{\circ}$ and allowed to cool once more over the sulphuric acid and again weighed.

After the dry weights had been obtained in this way, the briquettes were transferred successively to the second and to the third desiccators, their weights being determined after remaining in each desiccator for 24 hours. They were finally placed in the fourth desiccator over the pure water where they were allowed to remain for 120 hours, weighings being made every 24 hours. The results of this study are displayed in table $I$, the gains in weight in each instance being expressed in terms of per cent of the weight of the dry briquette. ${ }^{14}$

From these results it is evident that cooling in a dry atmosphere is essential to the most accurate results. Allowing the briquette to cool in the rojm or to stand for some time in the room may introduce errors in the "dry weight" up to as high as one per cent, depending upon the nature of the body, the humidity of the air at the time, and the period elapsing before the "dry weight" is taken.

17. Adsorbed Air. - In order to determine the amount of dry air which would be adsorbed by the body employed in the tests, three red-hot briquettes were transferred directly from the furnace to a previously heated hard glass tube. This tube was then evacuated to an $\mathrm{X}$-ray vacuum and allowed to cool until its weight was constant to $0.1 \mathrm{mg}$. for 24 hours. Dry air was then admitted and the weight again determined as soon as pressure equalization had

$14 \mathrm{Cf}$. the results of Mellor and Holdcroft (The Chemical Constitution of the Kaolinite Molecule. Staffordshire "Collected Papers," 1, 287. Griffin and Co., London, 1914) on the hydroscopicity of dry clay powder; and those of Day and Allen ( $A m$. J., Sci., 19, 93(1905)) on powdered minerals, which show that orthoclase powder will adsorb, from the atmosphere of the room, moisture up to some 0.7 per cent of its weight. 


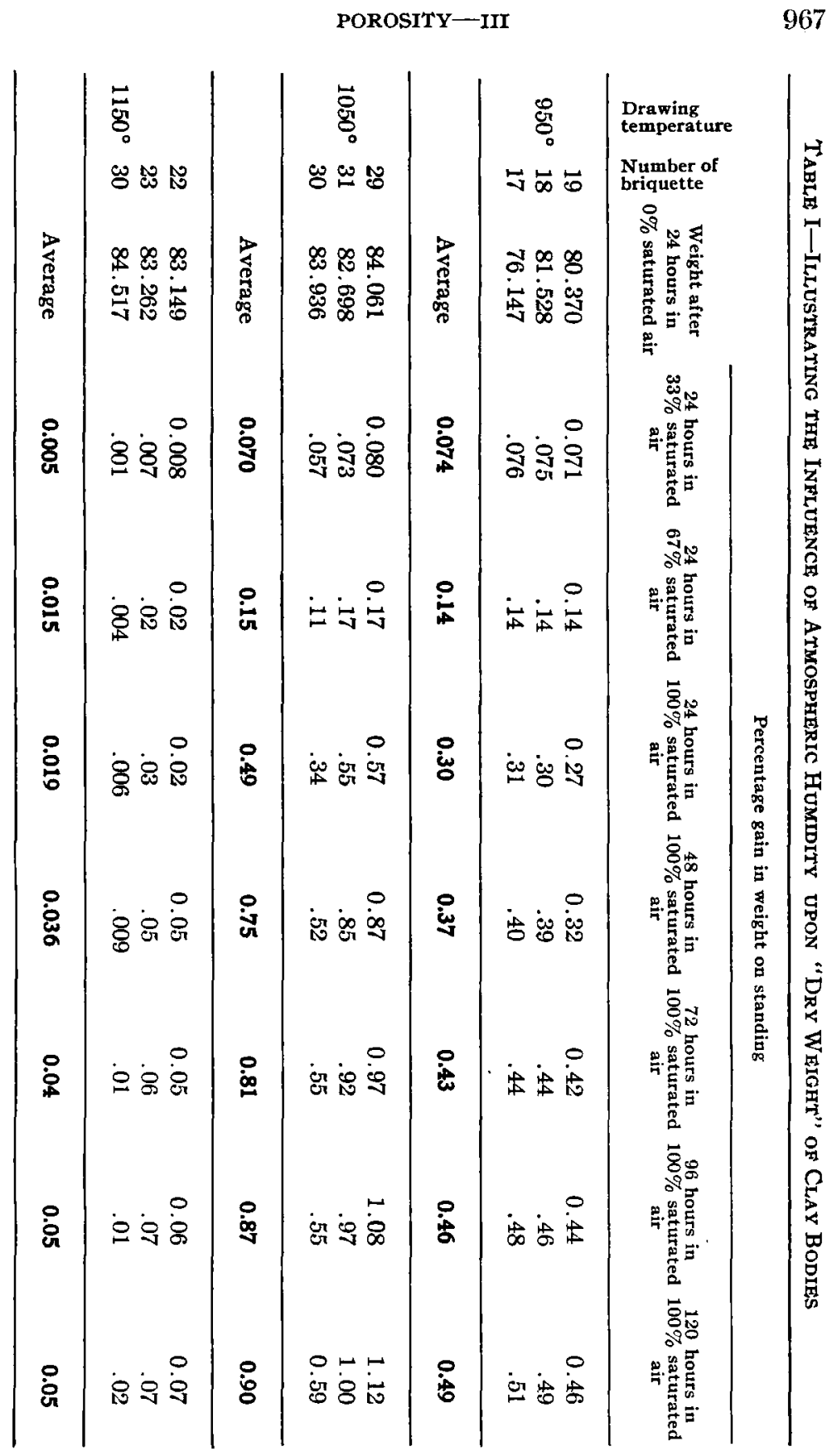


taken place. This process was repeated daily for 9 days. At first a slight inrush of air occurred each time the tube was opened to the atmosphere. 'This gradually diminished, and at the end of 9 days equilibrium had been reached and the weight no longer changed. The total increase in weight during this period was only $6 \mathrm{mg}$. in a total weight of 437 grams. The weight-in-air thus obtained was reduced to vacuo, and the calculated weight-invacuo thus obtained agreed with the observed weight-in-vacuo within the experimental error. In some additional experiments in which an attempt was made to estimate the amount of adsorbed air by releasing it into a vacuum positive results were obtained, but the amounts found were too small to affect appreciably the dry weight of a briquette.

It is thus evident that no significant error can arise from adsorbed air in the case of burned clay bodies.

We know, however, that many porous materials and powders are capable of taking up large quantitites of air and other gases. ${ }^{16}$ This is true, for example, in the case of the colloidal silica developed by Patrick ${ }^{16}$ for war purposes, also in the case of certain minerals such as the zeolites and chabazites which after dehydration were found by Friedel ${ }^{17}$ to absorb 1.8 per cent of their own weight of dry air. It can not be said with certainty, therefore, that all ceramic bodies will not adsorb appreciable quantities of air, although this will probably be true of most of them after they have been fired above red heat. (Cf. Sec. 68 below.)

18. Adsorption of Water Vapor from "Dry" Air.-Although not capable of adsorbing significant quantities of air, burned clay bodies have a great avidity for moisture, as is evident from the experiments described in the Section 16 . This was illustrated in a still more striking manner by the three briquettes employed in the above experiment. After removal from the hard glass tube, they were placed immediately in a desiccator and allowed to stand for 12 hours over $\mathrm{CaCl}_{2}$. They were then weighed and found to

${ }^{15}$ For bibliography and review of this subject see Scheringa, K., Pharm. Weekblad., 56, 94(1919).

${ }^{16}$ Patrick, J. Ind. Eng. Chem., 2, 97(1919); J. Am. Chem. Soc., 42, 947 (1920).

${ }^{17}$ Friedel, Ch., Compt. rend., 122, 1006(1895). 
have gained 9 centigrams or 0.04 per cent in weight. The following results were obtained when "1.86 sp. gr." sulphuric acid was used in place of $\mathrm{CaCl}_{2}$ in the desiccator: Gain in weight for briquettes drawn at $950^{\circ}, 0.02$ to 0.04 per cent; $1050^{\circ}, 0.08$ to 0.11 per cent; $1150^{\circ}, 0.05$ to 0.06 per cent; 48 hours in desiccator.

It is evident from these results that a perfectly dry piece of burned clay is a more powerful drying agent than calcium chloride or sulphuric acid, since it will take water away from either of these materials. ${ }^{18}$ The gain in weight under these conditions, while interesting as a phenomenon, is, of course, too small to have any practical significance in connection with porosity determinations.

\section{Comparison of the "Boiling-in-Vacuo" and the "Boiling- in-Air" Methods for Determining Porosity}

19. Boiling-in-Vacuo.-The dry briquettes prepared as described above were placed in a filter bottle connected with a separatory funnel filled with distilled water. The air pump employed was a small rotary high vacuum pump driven by a motor. The filter bottle containing the briquettes was first evacuated until the pressure fell to less than a millimeter. The stop-cock of the separatory funnel was then opened and the water, which had been previously boiled under a vacuum, was admitted until the briquettes were covered. The vacuum pump was continued in operation and the briquettes boiled at room temperature in this way for one hour, after which they were removed, wiped with a wet cloth and weighed. The percentage increase in weight due to the absorption of water in this process is shown in column 5 of table II.

After weighing, the briquettes were transferred to a porcelain casserole, covered with water, and boiled in the open air for one hour, after which they were allowed to cool in the water and were

${ }_{18}$ The $\mathrm{CaCl}_{2}$ used was taken from a bottle of the granulated material supplied for desiccator use. The sulphuric acid was the ordinary "c. P. 1.86" grade. Both products doubtless contained small amounts of water, and it was this water which was removed by the briquettes. Similar results to those given above are reported by Hillebrand, W. F. (Geol. Sunvey Bull., 422, $69(1916)$ ), in the case of a powdered mineral which, after dehydrating at $280^{\circ}$, gained $1 \frac{1}{2}$ per cent on standing in a desiccator over sulphuric acid. 


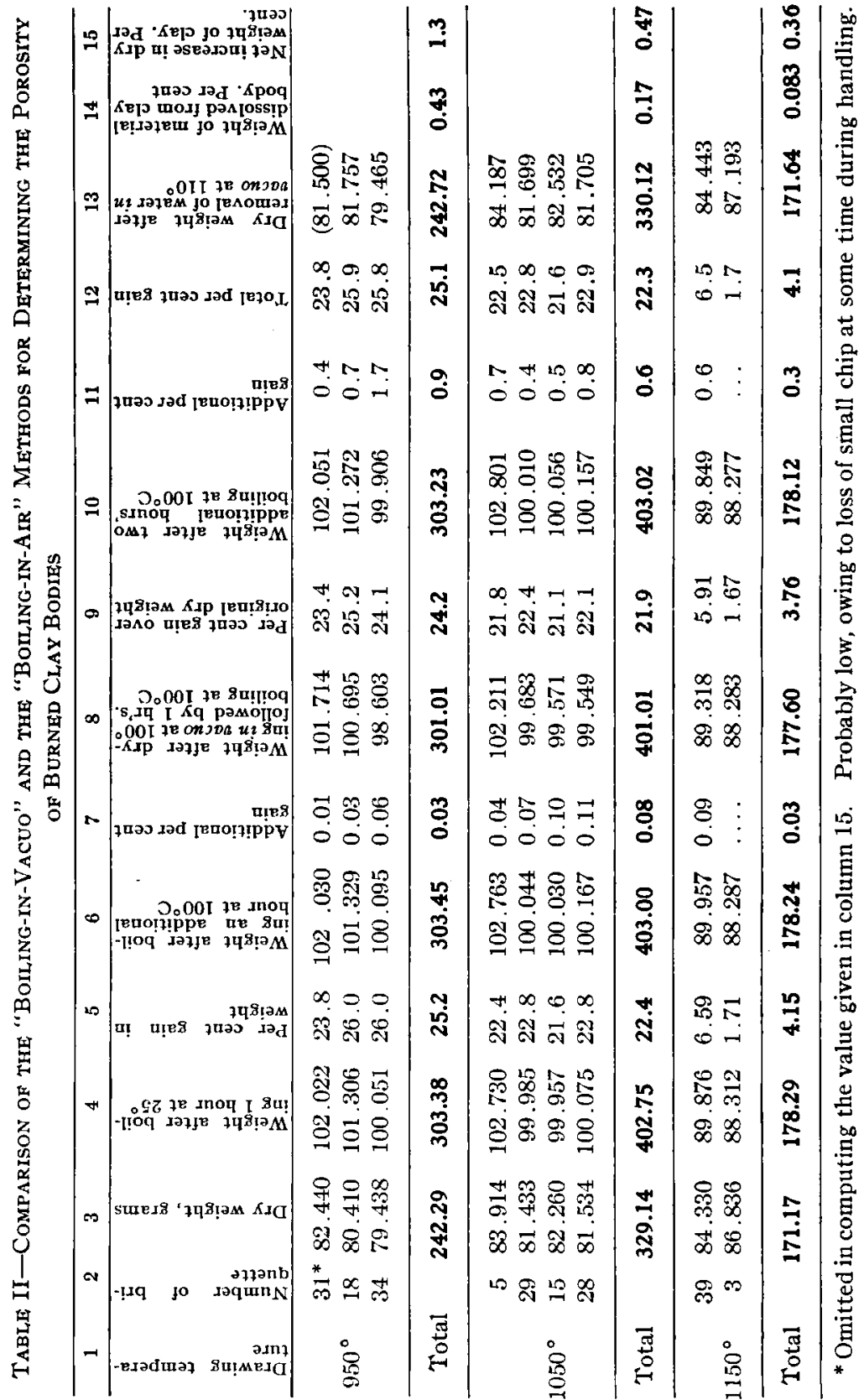


then removed, wiped with a wet cloth as before and weighed again. The additional increase in weight brought about by this process was practically nothing, as shown by the figures in column 7 of table II. In other words, the pores of the brick had apparently become completely filled with water during the vacuum treatment.

20. Boiling at $100^{\circ} \mathrm{C}$. - It was next desired to study the rate of absorption of water by the briquette when boiled at $100^{\circ}$. For this purpose the briquettes used in the previous experiment were dried at $100^{\circ}$ in a vacuum for one hour, after which they were transferred to a large porcelain casserole and boiled in water under atmospheric pressure for one hour and then, after cooling, were removed, wiped with a wet cloth and weighed. The per cent gain in weight due to the absorption of water in this process is shown in column 9 of table II. On comparing these figures with those of column 5 , it will be noticed that they are uniformly lower. In other words, one hour's boiling in the open air is not sufficient to completely fill the pores of the briquette with water. ${ }^{19}$ An additional two hours' boiling at $100^{\circ}$ was then carried out, and the resulting additional gain in weight is given in column 11 , the total gain resulting from the three hours' boiling being shown in column 12. On comparing the figures of column 12 with those of column 5 , it will be seen that they are substantially identical. In other words, three hours' boiling in the open air was required in order to obtain the same weight of the water-filled body as was obtained after one hour's boiling in the vacuum.

All of the water in which the briquettes had been boiled was carefully collected, filtered, and evaporated to dryness. A considerable amount of dissolved material was obtained in this way, the weight of the material dried at $110^{\circ}$ being shown in column 14 of table II. The briquettes were also dried again in vacuo at $100^{\circ}$ for 4 hours and weighed. These second dry weights are shown in column 13 of the table. On comparing these

${ }^{10}$ A similar result has been found by Loomis, G. A. (This J. 1, 393 (1918)), with fire-clay. The Report of the American Ceramic Society's Committee on Standards, Jan. 3, 1918, prescribed 45 minutes' boiling at atmospheric pressure for porosity determinations, but in a subsequent report issued in Feb., 1920, the time was increased to 2 hours. 
second dry weights with the first dry weights, it will be seen that on the average they are decidedly larger, in spite of the fact that appreciable quantities of material were dissolved out of the briquettes during the water treatment. If we add to the second dry weights, the weights of the materials dissolved from the briquettes and subtract from the sum the original dry weights, we obtain the net increase in weight of the clay as a result of the foregoing treatment. This net increase expressed in per cent is shown in column 15.

21. Nature of the Dissolved Material.-In order to determine the approximate chemical composition of the material dissolved from the briquettes, three fresh briquettes of each class were boiled for four hours at $100^{\circ}$ and the water was filtered, evaporated, and the residue partially analyzed. The results of these analyses for the $1050^{\circ}$ class are shown in table III.

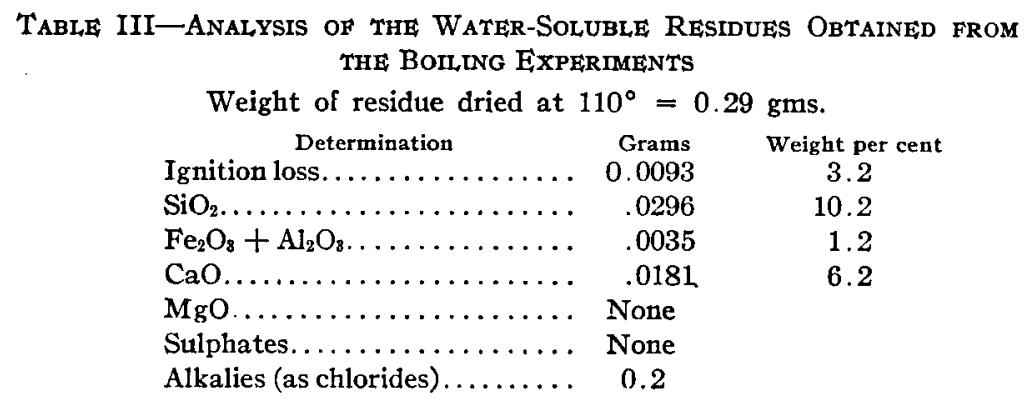

\section{Effect of Prolonged Immersion in Hot Water}

22. Purpose of the Experiment.-The increase in the "dry weight" of the test piece shown by the data in table II apparently points towards a gradual and steady rehydration of the clay when it is boiled in water at $100^{\circ}$. If such a rehydration actually occurs, of the magnitude indicated, it would evidently explain the results obtained by Walker. In order to secure additional evidence on this rehydration hypothesis, two series of experiments were carried out.

23. Immersion at $100^{\circ}$.- In one of these a $1050^{\circ}$ briquette was heated to redness, allowed to cool in a high vacuum, dry air 
admitted, and the dry weight of the briquette determined without removing it from the vacuum tube. It was then allowed to stand in a desiccator, first over $\mathrm{CaCl}_{2}$ and then over water, and the increase in weight observed. It was finally subjected to prolonged boiling at $100^{\circ}$, the dissolved matter collected and weighed, and the briquette finally dried for 3 hours in vacuo at $100^{\circ}$, weighed, ignited to red heat and weighed again. The results are shown in table IV and in figure 2.

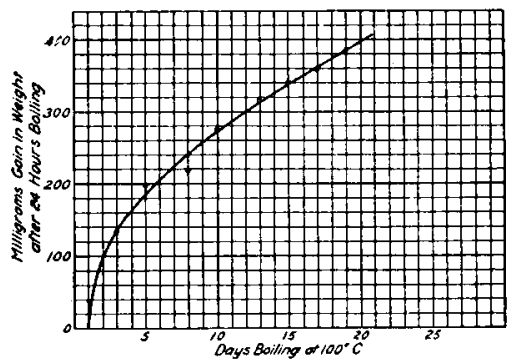

FIG. 2.-Rate of water absorption on prolonged immersion at $100^{\circ} \mathrm{C}$.

TABLE IV-Rehydration OF BRIQUETTE No. 32 (DRAWN AT $1050^{\circ}$ )

Dry weight after heating to $1000^{\circ}$ and cooling in high vacuo $81.625 \mathrm{gms}$.

Increase in weight (expressed in per cent of dry weight) produced by

Standing 12 hrs. over calcium chloride................... 0.04

Standing 72 hrs. over water........................... 47

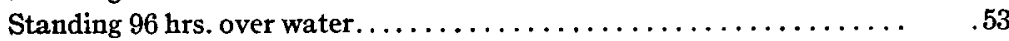

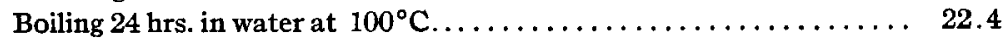

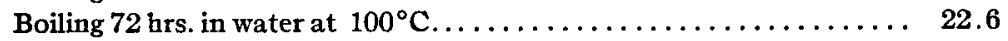

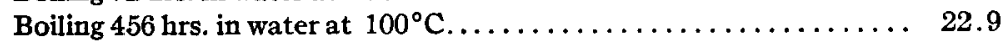

Loss of dissolved material........................ -0.36

The above treatment followed by drying in vacuo at $100^{\circ}$ for 3 hours... .91

Plus material dissolved...................................

The above treatment followed by two ignitions at red heat........ 0.2

24. Immersion at $200^{\circ}$.-For the experiments on the effect of prolonged immersion at $200^{\circ} \mathrm{C}$, two briquettes were heated in an electric furnace to $1000^{\circ}$, allowed to cool in a desiccator over $\mathrm{CaCl}_{2}$ and their dry weights determined. They were then placed in a porcelain dish and covered with distilled water. The dish was placed in an autoclave containing an excess of water, and this was heated to $200^{\circ}$ and kept at that temperature for 15 hours.

After cooling, the autoclave was opened, the briquettes removed, the fragments collected in a filter, and the water evaporated to dryness to obtain the dissolved material. All the material thus obtained was dried at $120^{\circ}$ and weighed. The increase in weight over the original dry weight amounted to 1.5 grams or 0.87 per cent. 
25. Discussion of the Results.-As a result of these experiments it seems to be established beyond question that "burned" clay slowly rehydrates in contact with water, the extent of the rehydration naturally being dependent upon time, temperature, and the nature and condition of the body.

Since the experiments here described were completed, there has been published an account of an investigation by Laird and Geller $^{20}$ on the rehydration of clay. They found that clays calcined at low temperatures $\left(600^{\circ}\right.$ to $\left.800^{\circ}\right)$, could be rehydrated by prolonged heating with water at $200-270^{\circ}$. This also agrees with results secured by Mellor and Holdcrof $\mathrm{t}^{21}$ with kaolinite dehydrated at $600^{\circ}$.

We may, therefore, conclude that the "boiling-in-air" method for determining the porosity of burned clay products does not fulfill the requirements of a "standard reference method" as outlined in the introduction. ${ }^{22}$

\section{Interpretation of the Results and Their Bearing upon the Determination of Porosity}

26. The Sources of Error, their Magnitudes and Significance. -The magnitudes of the various sources of error studied in this investigation may be conveniently summarized for comparison by tabulating them in terms of the percentage error which they produce upon the corresponding porosity values. For example, if the true porosity is 20 per cent and the value found by an inaccurate procedure is 20.2 per cent, the corresponding error in the porosity itself is evidently 1 per cent. The results of this

${ }^{20}$ Laird and Geller, This J., 2, 828(1919).

${ }^{21}$ Mellor and Holdcroft, op. cit., p. 283.

${ }^{22}$ The American Society for Testing Materials in its "1921 Standards" prescribes five hours' boiling in the open air in determining the porosity of drain tile (p. 558) building brick (p. 578) and clay sewer pipe (p. 591). In the case of refractory materials, however (p. 623), a four hours' immersion in kerosene of known density at $25^{\circ} \mathrm{C}$ under a vacuum of 24 in. is prescribed. This degree of vacuum is not sufficient to boil the kerosene, and consequently will not materially shorten the time required for completely filling the pores. It might, however, cause some change in the density of the kerosene and possible consequent error, due to evaporation of the more volatile constituents. The error from this source is probably not significant for practical purposes, however. 
method of representation are shown in table $\mathrm{V}$ and figure 3, positive values indicating that the error in question gives too large a value for the porosity, and negative values, the reverse.

In making any deductions from the results shown in table $\mathrm{V}$ the following considerations should be kept clearly in mind: (1) The values given are approximate only, but their order of magnitude may be taken as substantially correct. (2) They apply only to the particular body investigated, and must not be taken as representative of ceramic bodies in general. Other bodies may be expected to show either larger or smaller errors from the factors in question, depending upon the character

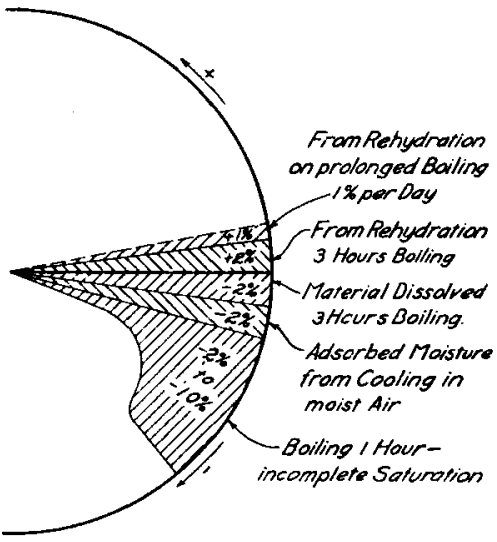

FIG. 3.-Typical magnitudes of various sources of error in the "boiling-inair" method.

of the body. With these facts in mind, we may proceed to a consideration of the significance of the data displayed in the table.

Table V-Iilustrating the Percentage Error in a Porosity Determination, Produced by Each of the Factors Indicated

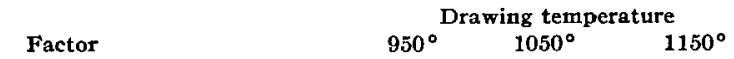

Cooling 12 hrs. over $\mathrm{CaCl}_{2}$ or $\mathrm{H}_{2} \mathrm{SO}_{4} \ldots \ldots . \quad$ About -0.2 per cent

Cooling 24 hrs. in $33 \%$ sat. air.......... $-0.3-0.3-0.06$

Cooling $24 \mathrm{hrs}$. in sat. air........... $-1 . \quad-2 . \quad-0.2$

Boiling $1 \mathrm{hr}$. at $25^{\circ} \mathrm{C} \ldots \ldots \ldots \ldots \ldots \ldots$, Taken as zero

Boiling $1 \mathrm{hr}$. at $100^{\circ} \ldots \ldots \ldots \ldots \ldots \ldots, 4.0 \quad-2.2 \quad-2$ to -10

Boiling 3 hrs. at $100^{\circ}$ :

(a) From rehydration........... +1.7 +0.76 +2.0

(b) From material dissolved......... $\quad-1.7 \quad-0.76 \quad-2.0$

Prolonged boiling at $100^{\circ}$ :

(a) From rehydration (See figure 3) .. $\quad-\quad$ About

+1 per

cent per

day af-

ter the

1 st day

(b) From material dissolved....... Up to -2 per cent, probably all during the 1 st two days 
27. Method of Cooling the Test Piece.-The most accurate method of obtaining the true dry weight of the test piece is, of course, to cool it in a perfect vacuum, as evident from the data in table IV. The error introduced by cooling in a desiccator over sulphuric acid or calcium chloride is, however, not large enough to have any significance as far as porosity measurements of most ceramic products are concerned. In fact, it may be doubted whether the adsorption of a small quantity of water vapor is really a source of error at all. The great avidity displayed by dry clay for water vapor shows that the first layer of water taken up from the surrounding atmosphere is very strongly held by the clay surface. This most strongly held adsorption layer is perhaps only one molecule deep ${ }^{23}$ all over the exposed surface, and the water in this layer may have a density very much greater than unity, a density in fact corresponding to that which would be the result of a large increase of pressure.

Since it is probable that nearly all of such a compression would be borne by the first one or two layers of molecules next the surface, it is not unreasonable to suppose that the porosity results obtained would be fully as accurate, if this first surface layer could be adsorbed before the "dry weight" of the test piece is taken, and its weight, which would be small, neglected in comparison with the total weight of absorbed water. Since, however, there is no way of telling in advance exactly what condition of drying will give just this layer, neither more or less, the best that can be done in general is to prescribe some arbitrary but uniform method of cooling the test piece.

In order to obtain some information upon which to base the formulation of a suitable procedure for cooling the test piece preparatory to taking its dry weight, the following experiments were carried out:

A disk $(15 \mathrm{~cm}$. in diameter and $5 \mathrm{~mm}$. thick) of a white ware body fired at cone 8 and having a porosity of about 60 per cent,

${ }^{28}$ Cf. Langmuir, J. Am. Chem. Soc., 40, 1361(1918) and 39, 1848(1917); also McGavack and Patrick, Ibid., 42, 968(1920); Lamb and Coolidge, Ibid., 42, 1165(1920); and Washburn, "Introduction to the Principles of Physical Chemistry," 2nd Ed., 425-30. McGraw-Hill Book Co., N. Y., 1921. 
was cleaned, weighed ( $133.422 \mathrm{gms}$.$) , heated to 1000^{\circ}$, transferred to a vacuum desiccator over 95 per cent $\mathrm{H}_{2} \mathrm{SO}_{4}$, allowed to cool 12 hours, and again weighed. Its "dry weight" obtained in this way was $132.860=0.002$ grams, and it gained very rapidly while in the balance case, although the latter had a dish of sulphuric acid in it. The dry piece was then placed over water, in order to saturate itself with water vapor, and weighed again. This time it lost weight very rapidly while in the balance case, its weight, as nearly as could be determined, being $\mathbf{1 3 3 . 4 5 0}$ grams.

The piece was finally returned to the vacuum desiccator containing the 95 per cent sulphuric acid and weighed at intervals to determine the rate of loss of adsorbed water.

In four hours its weight had fallen to 132.950 grams. Twenty hours later it had fallen to 132.930 grams, and an additional 48 hours' standing decreased it to 132.910 grams, after which it remained constant for 48 hours at 132.910 grams or 0.055 gram more than its original "dry weight." This 0.055 gram of adsorbed water is evidently held very firmly since it is not removed in 5 days by 95 per cent sulphuric acid.

The result of the above experiments suggests the following as a sufficiently exact procedure for securing the "dry weight" of the test piece for porosity determinations when water is used as the absorption liquid:

Place the test piece in a desiccator over 95 per cent sulphuric acid and allow it to remain there until it has reached "constant weight." If, as is ordinarily the case, the weighings are made to the nearest decigram, then it is evident from the above experiments that, for a very porous body, a few hours ( 2 or 3 ) in the desiccator is sufficient for the attainment of "constant weight." Previous to being placed in the desiccator, the test piece should be in contact with moist air for a short time in order that it may have an opportunity to adsorb its surface layer of water. If, after removal from the furnace, it is allowed to stand in the room until completely cold, this will ordinarily suffice to give it the requisite amount of adsorbed water. Evacuation of the desiccator will, of course, shorten the time required to attain constant weight. 
28. The Vacuum Method of Porosity Measurement.-If the water absorption method is to be used at all as a permissible method for determining porosity where accurate results are desired, the vacuum method is obviously the most trustworthy procedure which can be employed. The most accurate method of carrying it out is obviously the following:

Place the test pieces, whose dry weights have been determined, in the vacuum vessel and evacuate the air until, on closing the connection to the pump, the manometer reading remains constant. Then close the connection to the pump and admit enough airfree, cold, distilled water to cover the test pieces. Disconnect the pump, and immediately break the vacuum. Allow the test pieces to soak until the water has completely penetrated the pores; then remove the test pieces, "dry" by wiping with a very damp towel or with some non-absorbent material, ${ }^{24}$ and weigh. Evaporation during weighing may be prevented by inclosing the test piece in a weighing tube.

In order to carry out the method in the above manner, a good vacuum pump is necessary. The degree of vacuum required in any given case may be computed as follows: Let $B$ be the barometric pressure, $A$ be the fractional accuracy desired in the porosity value, and $p$ be the pressure required in the vacuum vessel. Then from the laws of gases we find, for the extreme case of no channel pores,

$$
p: \mid>A B
$$

Thus if the accuracy required is 1 per cent of the porosity itself, then for $p$ we find $7.6 \mathrm{~mm}$. or 0.3 inch. With the above procedure, employing cold water and avoiding boiling or stirring, it is evident that both rehydration and solution would be reduced to a minimum, since the temperature is low and any dissolved material can escape from the test piece only by diffusion, which is a relatively slow process. The method could thus probably be safely employed even with under-burned bodies, if desired. Nothing is to be gained by employing hot water.

${ }^{24}$ Or better, by completely immersing the piece for a moment in mercury. This method was suggested by Prof. C. W. Parmelee. It has the advantage of automatically removing the surface water, as well as the water from those surface pores which are large enough to be penetrated by the mercury, thus eliminating the personal equation from the procedure. 
If the pump available is not powerful enough to give the vacuum required for the above procedure, then the best method of operation is simply to boil the test piece in vacuo for the minimum period necessary ${ }^{25}$ to effect complete saturation within the desired limit of accuracy. It is impossible to specify a length of time for this boiling process which will apply to every case.

29. Necessity for a Soaking Period.-In the above procedure no definite specification as to soaking period is given, nor is such an exact specification possible in general. Time is required for the water to penetrate the smallest pores of the body, and the smaller and more numerous these pores are, the greater will be the time required for complete saturation. The driving pressure behind the water is atmospheric pressure plus the surface tension pressure, and for very small pores is not sufficient to produce complete penetration except after very long periods of soaking.

The theory of the rate of penetration of porous bodies by liquids has been discussed by the senior author in another publication. ${ }^{26}$ This theory shows that the amount of liquid which penetrates a porous body is proportional to the square root of the time of soaking and to the square root of the ratio, $\frac{\gamma}{\eta}$ of the surface tension of the liquid to its viscosity, for all cylindrical pores except those of molecular dimensions. Thus, if the pores of a briquette filled to the extent of 10 per cent in 2 minutes, it would require at least 3 hours and 20 minutes' soaking in order to fill them completely, assuming them to be of uniform dimensions.

The time required for complete penetration can be greatly reduced by the use of external pressures of several hundred atmospheres, as has been shown by Cude and Hullett, ${ }^{27}$ and for very dense bodies with excessively fine pores, the use of such pressures offers the only hope of securing accurate porosity values by any absorption process. Equipment for producing such pressures is not ordinarily available in ceramic laboratories at the present time, however, and fortunately for many cases met with in actual ${ }_{25}$ To be found by trial. See Sec. $30 b$ below. (1921).

${ }^{26}$ Washburn, "The Dynamics of Capillary Flow," Phys. Rev., 17, 280

${ }^{27}$ Cude and Hullett, J. A m. Chem. Soc., 42, 400(1920). 
practice, it is not important to include in the measured porosity these very small pores. ${ }^{28}$

Until further data are available, therefore, it would seem best to prescribe a somewhat arbitrary soaking period, which can be ascertained in the following manner:

30. Determination of the Minimum Soaking Period.(a) By Calculation.-The time required for water to penetrate a distance, $l$, along a small cylindrical capillary is given by the expression $^{29}$

$$
t=\frac{l^{2}}{12}
$$

where $r$ is the radius of the capillary and $z\left(=\frac{\boldsymbol{\gamma}}{2 \eta}\right)$ is the coefficient of penetrance or the penetrativity of the liquid. For water at room temperature

$$
z=\frac{74}{0.02}=3700 \mathrm{~cm} . / \mathrm{sec} \text {. }
$$

For $l$ we may safely write $1 / 2 l_{\max }$, where $l_{\max }$ is the length of the longest straight line wholly within the test piece. The value of $r$ would depend upon the character of the body and the accuracy demanded. Thus for common clay products we might write $r=0.5 \times 10^{-4} \mathrm{~cm}$., that is, we would be satisfied as soon as all pores, with diameters not less than $0.001 \mathrm{~mm}$., were filled with the liquid. With these assumptions equation (2) becomes

$$
t=\frac{4 l^{2}{ }_{\max }}{3}
$$

Thus for a briquette $4 \mathrm{in}$. long, we would have $l_{\max }=12 \mathrm{~cm}$. and hence, $t=192 \mathrm{sec}$. $=3.2$ minutes.

With a material such as electrical porcelain for high tension insulators, it is necessary to take account of pores of much smaller diameter probably down to $10^{-5} \mathrm{~mm}$. which is about a hundred

${ }^{28}$ Such materials as high tension electrical insulators, spark plug bodies, etc., of course, constitute exceptions to this statement, and the results of Cude and Hullett, referred to above, point to the desirability of employing a high pressure equipment for porosity studies on such bodies, or better the substitution of a gas in place of the liquid as the pore filling agent. This latter method will be described in the sixth paper of this series.

${ }^{99}$ Washburn, op. cit., p. 280. 
times molecular dimensions. Since the soaking time varies inversely as the pore diameter, the soaking time would be multiplied 100 fold, if pores as small as $10^{-5} \mathrm{~mm}$. were included. Thus, for the briquette used in the above example, this would mean a soaking time of 5 hours, at least, thus emphasizing the necessity of employing high pressures when determining with accuracy the porosity of highly vitrified bodies by the absorption method.

(b) By Direct Experiment.- The calculated value obtained as described above is a minimum value only, because the calculation takes no account of the possible presence of pocket pores or pores whose diameters increase toward the interior of the body. Such pores would fill more slowly than the cylindrical pores. The actual soaking period required can be determined by suspending the immersed piece from the arm of a sensitive balance and noting the time required for it to attain its maximum weight. This maximum weight can, if desired, be determined in advance by the method which will be described in the sixth paper of this series.

31. Boiling at Atmospheric Pressures.-This method is evidently not sufficiently reliable for a standard reference method. In the cases studied, a one hour's boiling failed to produce complete saturation by from 2 to 10 per cent. Three hours' boiling gave the correct result, but only because the loss of weight due to dissolved material ( 1 to 2 per cent) just compensated for the gain in weight due to rehydration. Since there is no way of predicting in advance what period of boiling is necessary in order that these two errors shall just cancel each other, it is evident that the method should be rejected entirely as a general standard. There are, of course, many cases where it can be safely employed and will give results quite accurate enough for the purpose in hand. In any case where it is so employed, however, evidence that the errors are in fact negligible for the purpose in hand should be available. In this connection the following experience with the "boiling-in-air" method is worthy of mention. A standard size test piece of a stoneware body after firing to cone 10 was boiled in distilled water for 5 hours under atmospheric pressure. After removal and weighing it was found to have absorbed an amount of water corresponding to a porosity of 3 per cent. The actual porosity 
of this same test piece was, however, later shown to be 15 per cent.

Part IV of this paper will deal with the use of petroleum products as absorption liquids.

Department of Ceramic finginegring

UNIVERSTTY OF IGLINOIS

URBANA, It,L.INOIS 